\title{
Posterior urethral valves in South African boys: Outcomes and challenges
}

\author{
K L Petersen, MB BCh, DCH, DTM\&H, FCPaed (SA), MMed (Paed), Cert Nephrology (SA) Paed; D P Moore, MB BCh, FCPaed (SA), \\ MMed (Paed), Cert ID (Paed) SA, MPhil (Paed ID); U K Kala, MB BCh, DCH, FCPaed (SA), Cert Nephrology (SA) Paed \\ Department of Paediatrics, Chris Hani Baragwanath Academic Hospital and Faculty of Health Sciences, University of the Witwatersrand, \\ Johannesburg, South Africa
}

Corresponding author: KL Petersen (karen.petersen@wits.ac.za)

\begin{abstract}
Background. Posterior urethral valves (PUV) are a common cause of congenital obstructive nephropathy. The outcome of patients with PUV at Chris Hani Baragwanath Academic Hospital in Johannesburg, South Africa, has not been documented previously.

Objectives. To describe the outcome of patients diagnosed with PUV over a 29-year period from January 1985 to December 2013, and to analyse risk factors for chronic kidney disease.

Methods. This was a retrospective record review of boys aged $<14$ years diagnosed with PUV at Chris Hani Baragwanath Academic Hospital. PUV was diagnosed by a voiding cystourethrogram (VCUG) and/or at cystoscopy. Valves were resected primarily or after vesicostomy. The glomerular filtration rate was calculated using the Schwartz formula, and stratified as normal or decreased for age at presentation and at the final visit.

Results. Records of 181 patients were analysed. The diagnosis was made during the first year of life in 139 patients (76.8\%). Clinical presentation included urinary tract infection (UTI) in 109 patients (60.2\%), palpable bladder in 98 (54.1\%), palpable kidney in 85 (46.9\%), and poor urinary stream in $78(43.1 \%)$. An ultrasound scan was reported normal in $10.9 \%$. Vesicostomy was performed in 80 patients (44.2\%) and primary valve ablation in $101(55.8 \%)$, with vesicostomy being more prevalent in the pre-2000 era. The median duration of follow-up was 21 months (interquartile range 5 - 79) and renal outcome at last visit was normal in 117 patients (64.6\%). The presence of bladder diverticula was associated with a favourable renal outcome. Thirteen patients (7.2\%) died, and 102 (56.3\%) defaulted from follow-up.

Conclusions. PUV frequently presents with UTI and palpable bladder and/or kidneys. Findings on ultrasound were normal in $10.9 \%$ of our patients with PUV. A VCUG is indicated in the presence of palpable kidneys or bladder even if the ultrasound scan is normal. Bladder diverticula as a pressure-release mechanism are renoprotective. Vesicostomy or primary valve ablation did not affect final renal outcome. Chronic kidney disease occurred in $34.8 \%$ of patients after surgical correction. Adherence to scheduled appointments is problematic in this population. Long-term follow-up is mandatory.
\end{abstract}

S Afr Med J 2018;108(8):667-670. DOI:10.7196/SAMJ.2018.v108i8.12934

Posterior urethral valves (PUV) occur in 1:5 $000-1: 8000$ boys. ${ }^{[1]}$ This congenital abnormality of the membranous urethra results in bladder outlet obstruction that may range from mild to severe. ${ }^{[2]}$ Early diagnosis and management are essential to prevent progressive renal disease. ${ }^{[3]}$ Antenatal diagnosis of PUV may be suspected if the ultrasound scan shows hydronephrosis, a distended bladder and a dilated posterior urethra, often associated with oligohydramnios. ${ }^{[1,4]}$ Postnatal diagnosis is confirmed by a voiding cystourethrogram (VCUG) in the presence of a dilated posterior urethra, often with bladder trabeculation and diverticula. ${ }^{[5]}$ Secondary vesicoureteric reflux (VUR) may be present. ${ }^{[6]}$

The diagnosis of PUV may be difficult for many reasons. Firstly, the symptom of dribbling urine may not be observed in partial obstruction, ${ }^{[7]}$ and specific enquiry about the urinary stream is often omitted. Secondly, it is possible to miss the diagnosis on ultrasound. The ultrasound finding of hydronephrosis is not universal, ${ }^{[8]}$ may be less obvious if performed after prolonged catheterisation, and is operator dependent. Bladder wall thickness is not routinely reported. Thirdly, the VCUG is technically difficult in paediatric patients, with voiding films not easily obtained and often performed with the urinary catheter in situ. The VCUG is also limited by interobserver variability ${ }^{[9]}$ Other factors limiting the diagnosis include technical aspects of cystoscopy. Visualisation of the valves or valve remnants requires an experienced endoscopist. ${ }^{[10]}$
Renal protective factors have been described that allow pressure popoff mechanisms in the presence of PUV. These include unilateral VUR with renal dysplasia, and the presence of urachus, ascites, urinoma and bladder diverticula. ${ }^{[1]}$ The surgical management of PUV has evolved with advances in equipment. ${ }^{[12]}$ Primary endoscopic valve resection is preferred over vesicostomy to avoid bladder scarring and allow normal bladder cycling, ${ }^{[13]}$ but in the absence of small resectoscopes, a temporary vesicostomy could be performed to relieve pressure on the kidneys. ${ }^{[1,15]}$ Renal outcome is favourable for mild cases with normal serum creatinine at presentation, ${ }^{[16]}$ but for patients with severe obstruction and possible renal dysplasia the prognosis is guarded. ${ }^{[17,18]}$ Initial surgical choice of vesicostomy or valve resection does not appear to affect renal outcome. ${ }^{[19,20]}$ The valve bladder is diagnosed when there is persistent hydroureteronephrosis after valve ablation. ${ }^{[21]}$

\section{Methods}

This was a retrospective descriptive and analytical study spanning 29 years, from January 1985 to December 2013. Records for all boys aged $<14$ years diagnosed with PUV in the Department of Paediatrics at Chris Hani Baragwanath Academic Hospital, a large tertiary academic hospital in Johannesburg, South Africa (SA), were reviewed. PUV was diagnosed if the posterior urethra showed typical dilatation on VCUG, and/or if valves were visualised at cystoscopy. Serum creatinine was measured by the National Health Laboratory Service 
using the Jaffe reaction on a Hitachi cobus c701/702 analyser (Roche, Germany). The glomerular filtration rate (GFR) was calculated (cGFR) using the Schwartz formula ${ }^{[22]}$ and classified as normal or decreased for age. ${ }^{[23]}$ Demographic data, clinical findings, and radiological and surgical reports were retrieved from the archived clinical files and analysed using R version 3.2.3 statistical software. ${ }^{[24]}$ Continuous variables were expressed as percentages, medians and interquartile ranges (IQRs), where appropriate. Categorical data were analysed using the $\chi^{2}$ test or Fisher's exact test, where appropriate. Two-sided $p$-values of $<0.05$ were considered significant.

Approval was obtained from the Human Research and Ethics Committee of the University of the Witwatersrand (ref. no. M070206) and from the hospital. Part of the data were submitted towards a MMed degree (KLP).

\section{Results}

A total of 192 boys with PUV were identified during the study period. Eleven were excluded from analysis owing to insufficient records $(n=2)$, refusal of surgery $(n=5)$ and high diversion procedures $(n=4)$. The median age at diagnosis for the 181 remaining children was 2 months (range 0 - 143 months, IQR 0 - 11 months). The diagnosis was suspected on an antenatal ultrasound scan in 8 patients (4.4\%). One hundred and thirty-nine patients $(76.8 \%)$ presented in the first year of life (Table 1).

\section{Clinical presentation}

The commonest findings at presentation were urinary tract infection (UTI) in 109 patients (60.2\%), palpable bladder in 98 (54.1\%) and

\begin{tabular}{ll} 
Table 1. Age at diagnosis & \\
\hline & $\boldsymbol{n}(\%)$ \\
\hline Up to 1 month & $77(42.5)$ \\
$>1$ month -12 months & $62(34.3)$ \\
$>12$ months -60 months & $30(16.6)$ \\
$>60$ months & $12(6.6)$ \\
Total & $181(100.0)$
\end{tabular}

palpable kidney in 85 (46.9\%); 30.3\% of the patients (55 of 181) were underweight for age. Children aged $<1$ year were significantly more likely than older children to present with palpable kidneys (odds ratio (OR) 2.77, 95\% confidence interval (CI) 1.31 - 5.84; $p=0.007$ ) and a distended abdomen (OR 3.69, 95\% CI 1.53 - 8.88; $p=0.002$ ), whereas older children more often presented with UTI (OR 6.89, 95\% CI 2.56 - 18.56; $p<0.001$ ) (Table 2).

\section{Radiography}

Ultrasound reports were available for 173 patients (95.6\%) and were reported to be normal in 19 (10.9\%). Unilateral or bilateral hydronephrosis was reported in 154 patients (89.0\%). Ultrasound of the bladder supported the diagnosis of PUV (thick walled, distended, trabeculation) in 57 reports (32.9\%).

VCUG reports were available for 161 patients (88.9\%). The bladder was reported normal in 31 (19.2\%), while bladder trabeculation was reported in $104(64.6 \%)$ and bladder diverticula in 61 (37.8\%). VUR was present in 65 patients (40.3\%), bilateral in 24 (14.9\%) and unilateral in 41 (25.4\%).

Interestingly, of 139 patients in whom an ultrasound scan showed hydronephrosis and who had VCUG reports available, only 62 (44.6\%) demonstrated VUR on VCUG. The urethra was reported normal in 3 patients who had valves diagnosed at cystoscopy. The VCUG voiding films for these 3 patients were obtained with the urinary catheter in situ.

\section{Surgical intervention}

Surgical intervention and outcome are shown in Table 3. Primary valve resection was performed in 101 patients $(55.8 \%)$ and vesicostomy in $80(44.2 \%)$. During the study period, the median age of primary valve resection was 7.8 months (IQR 2.4 - 28.9) and that for vesicostomy 1.2 months (IQR $0.7-3.2)(p<0.001)$. From the year 2000 onwards, the median age at valve ablation was 4.2 months, compared with 14.9 months before the year 2000. In infants $(n=139), 47$ (68.1\%) of 69 treated before the year 2000 underwent vesicostomy, compared with $31(44.3 \%)$ of 70 treated after the year 2000 (OR 2.69, 95\% CI 1.35 - 5.37; $p=0.005$ ).

Table 2. Clinical findings stratified by age at presentation

\begin{tabular}{|c|c|c|c|c|c|}
\hline & \multicolumn{2}{|c|}{ Age group } & \multirow[b]{2}{*}{ OR } & \multirow[b]{2}{*}{ 95\% CI } & \multirow[b]{2}{*}{$p$-value ${ }^{*}$} \\
\hline & $<12$ months $(N=139), n(\%)$ & $\geq 12$ months $(N=42), n(\%)$ & & & \\
\hline UTI & $72(51.8)$ & $37(88.1)$ & 0.15 & $0.05-0.39$ & $<0.001$ \\
\hline Poor urinary stream & $54(38.8)$ & $24(57.1)$ & 0.48 & $0.24-0.96$ & 0.036 \\
\hline Distended abdomen & $59(42.4)$ & $7(16.7)$ & 3.69 & $1.53-8.88$ & 0.002 \\
\hline Palpable bladder & $76(54.7)$ & $22(52.4)$ & 1.10 & $0.55-2.19$ & 0.794 \\
\hline Palpable kidney & $73(52.5)$ & $12(28.6)$ & 2.77 & $1.31-5.84$ & 0.007 \\
\hline Underweight for age & $42(30.2)$ & $13(31.0)$ & 0.97 & $0.46-2.04$ & 0.928 \\
\hline
\end{tabular}

Table 3. Surgical intervention and renal outcome at last visit

\begin{tabular}{lll}
\hline & Primary valve ablation & Vesicostomy \\
\hline Total, $n(\%)$ & $101(55.8)$ & $80(44.2)$ \\
Age at surgery (months), median (IQR) & & $1.3(0.8-3.4)$ \\
$\quad$ Before the year $2000(n=94)$ & $14.9(3.1-40.2)$ & $1.0(0.6-3.1)$ \\
$\quad$ After the year $2000(n=87)$ & $4.2(2.3-16.9)$ & $52(65.0)$ \\
Renal outcome normal ${ }^{*}, n(\%)$ & $65(64.3)$ & $28(35.0)$ \\
Renal outcome decreased ${ }^{*}, n(\%)$ & & \\
IQR $=$ interquartile range; cGFR $=$ calculated glomerular filtration rate. & &
\end{tabular}




\section{Renal outcome}

The cGFR at the last visit was normal in 117 patients (64.6\%), abnormal in $63(34.8 \%)$ and unknown in 1 . In 70 patients $(53.4 \%)$ who started off with a decreased cGFR $(n=131)$, the final cGFR improved to normal for the duration of the study period. In univariate and multivariate analyses, the presence of bladder diverticula at baseline was the only factor associated with a favourable renal outcome (Table 4 ).

The median duration of follow-up was 21 months (range $0-245$, IQR 5 - 79). Thirteen patients (7.2\%) died during the study period, 10 with renal failure and 3 with normal renal function. Sixteen patients $(8.8 \%)$ were transferred out, to the adult renal service $(n=4)$, to a transplant clinic $(n=6)$, and to other provinces $(n=6)$. Of 102 patients who did not return for scheduled appointments, 80 (78.4\%) had a normal cGFR at the last visit.

\section{Discussion}

This study documents the presentation and outcome of PUV in SA boys attending Chris Hani Baragwanath Academic Hospital over a 29-year period.

The low antenatal detection rate in this population reflects limited ultrasound screening and/or unbooked pregnancies. Seventy-seven per cent of patients were diagnosed in the first year of life. This contrasts with developed countries, where the diagnosis is made in utero in most cases.

The commonest presenting features in this population were UTI, palpable bladder, palpable kidney and poor urinary stream. These clinical findings should prompt investigation to exclude urinary obstruction in any patient. Ultrasound evaluation of the kidneys and bladder in patients with UTI should be mandatory in this population, where antenatal ultrasound for detection of congenital abnormalities is not done routinely. ${ }^{[25]}$ Guidelines from developed countries cannot routinely be applied to this population.

Unilateral or bilateral hydronephrosis on ultrasound was reported in $89.0 \%$ of patients, and only $44.6 \%$ of patients with hydronephrosis on ultrasound had associated VUR. Hydronephrosis not associated with VUR may be due to a thickened bladder wall limiting ureteric drainage into the bladder. $^{[2]}$ Importantly, the kidney ultrasound findings were normal in 19 patients (10.9\%). This could be due to mild obstruction, or to delay in imaging after prolonged bladder catheterisation. PUV would potentially remain undiagnosed in these patients unless a VCUG is performed when clinically indicated, such as in the presence of palpable kidneys or bladder.
In three patients the urethra was reported normal, with valves visualised and ablated at cystoscopy. Voiding films may be technically difficult in children who have no bladder control. Voiding films with a urethral catheter in situ may limit filling of the dilated posterior urethra with contrast, thus obscuring the presence of PUV. We recommend that the urethral catheter be removed when voiding films are obtained.

The patients in the vesicostomy group were younger than those in the primary valve resection group. This finding reflects the era before small resectoscopes in this historic group, which is borne out by the observation that infants treated in the pre-2000 era had 2.7-fold greater odds of undergoing vesicostomy than infants treated from 2000 onwards. In the past decade, primary valve ablation has almost exclusively been performed, and low-birth-weight neonates are catheterised until they weigh at least $3 \mathrm{~kg}$ to allow resection of the valves at cystoscopy. The choice of initial surgery did not affect the final renal outcome. Vesicostomy should be considered a viable treatment option in developing countries where small resectoscopes or surgical skill are not available.

In $53.4 \%$ of patients who started off with a low cGFR, there was improvement to normal renal function after surgical intervention for the duration of follow-up. This study supports previous observations that the initial serum creatinine level cannot be used to predict final renal function in boys with PUV. ${ }^{[26]}$ The presence of bladder diverticula on VCUG at baseline was associated with 51.0\% lower adjusted odds of poor renal outcome in this cohort, supporting the presence of bladder diverticula acting as a pressure-release mechanism preventing damage to the kidneys. The final visit cGFR was abnormal in $34.8 \%$ of patients at a median duration of follow-up of 21 months.

The low rate of adherence to scheduled hospital visits is not unusual in a developing country. ${ }^{[27,28]}$ Most of the patients who did not return to the clinic were from other provinces and neighbouring countries, and most of them had normal renal function at the last clinical evaluation.

\section{Study limitations}

This study is limited by its retrospective nature. In addition, patients at extreme ends of disease severity may not have been referred, resulting in referral bias. This includes patients with severe obstruction resulting in fatal pulmonary hypoplasia related to oligohydramnios, and those with mild obstruction. The poor adherence to scheduled appointments limits analysis of long-term outcomes. Nonetheless, the

Table 4. Analysis of renal outcome based on clinical and radiological characteristics at baseline

\begin{tabular}{|c|c|c|c|c|c|c|}
\hline & $\begin{array}{l}\text { Renal outcome } \\
\text { normal }^{*} \\
(N=117)\end{array}$ & $\begin{array}{l}\text { Renal outcome } \\
\text { decreased }^{*} \\
(N=63)\end{array}$ & OR $(95 \% \mathrm{CI})$ & $p$-value & $\begin{array}{l}\text { Adjusted } \mathrm{OR}^{\dagger} \\
(95 \% \mathrm{CI})\end{array}$ & $p$-value \\
\hline Age at presentation (months), median (IQR) & $2(0-10)$ & $2(0-10.5)$ & $0.99(0.98-1.00)$ & 0.147 & $0.99(0.98-1.00)$ & 0.120 \\
\hline Age at surgery (months), median (IQR) & $2.9(1.2-12.1)$ & $3.1(1.1-16.2)$ & $0.99(0.98-1.00)$ & 0.079 & & \\
\hline Age $<12$ months $(N=139), n(\%)$ & $91(65.5)$ & $48(34.5)$ & $1.09(0.52-2.24)$ & 0.809 & & \\
\hline Antenatal diagnosis $(N=8), n(\%)$ & $5(62.5)$ & $3(37.5)$ & $0.89(0.21-4.47)$ & 0.880 & & \\
\hline Ascites $(N=32), n(\%)$ & $24(75.0)$ & $8(25.0)$ & $1.80(0.78-4.54)$ & 0.185 & $1.76(0.75-4.50)$ & 0.213 \\
\hline Bladder diverticula $(N=61), n(\%)$ & $33(54.1)$ & $28(45.9)$ & $0.49(0.26-0.93)$ & 0.029 & $0.49(0.25-0.94)$ & 0.032 \\
\hline Urinoma $(N=13), n(\%)$ & $9(69.2)$ & $4(30.8)$ & $1.25(0.39-4.78)$ & 0.721 & & \\
\hline Urachus $(N=3), n(\%)$ & $1(33.3)$ & $2(66.7)$ & $0.26(0.01-2.80)$ & 0.279 & & \\
\hline VURD $(N=14), n(\%)$ & $7(50.0)$ & $7(50.0)$ & $0.52(0.17-1.60)$ & 0.246 & & \\
\hline Presented from 2000 to $2013(N=86), n(\%)$ & $58(49.6)$ & $28(44.4)$ & $1.22(0.67-2.28)$ & 0.511 & & \\
\hline
\end{tabular}


study highlights important aspects of this condition specific to this population, including the difficulties in diagnosis.

We recommend a screening ultrasound scan of the kidneys and bladder in children with documented UTI, since antenatal ultrasound for fetal abnormalities is not performed routinely in our population. Clinical signs of a palpable bladder and/or kidney warrant further investigation, since ultrasound findings may be normal in up to $11 \%$ of patients with PUV. We therefore also recommend that a VCUG should be performed if the ultrasound scan reveals hydronephrosis or a thickened bladder wall, or if the bladder and/or kidneys are palpable. Urodynamic studies, bladder diaries and serial ultrasound scans reporting bladder volumes are recommended to diagnose and manage the valve bladder.

\section{Conclusions}

The diagnosis of PUV may pose a challenge for various reasons. Patients with PUV frequently present with UTI and a palpable bladder and/or kidneys, and an ultrasound scan of the renal tract may be normal in a considerable proportion of patients. The clinical findings should determine the extent of radiological investigations in a boy with UTI. Chronic kidney disease is present in about one-third of patients after a median follow-up of 21 months following surgical correction. Long-term follow-up is therefore mandatory, but is not always adhered to in this population.

Acknowledgements. The authors wish to acknowledge the paediatricians, paediatric surgeons, radiologists and nurses involved in the care of the patients.

Author contributions. KLP: conception of research question, data collection, data analysis, manuscript preparation and revision, approval of final manuscript; UKK: conception of research question, data analysis, revision and approval of final manuscript; DPM: data analysis, revision and approval of final manuscript.

Funding. None.

Conflicts of interest. None.

1. Kumar S, Fisk NM. Distal urinary obstruction. Clin Perinatol 2003;30(3):507-519. https://doi. org/10.1016/S0095-5108(03)00060-5

2. Macpherson RI, Leithiser RE, Gordon L, Turner WR. Posterior urethral valves: An update and review. Radiographics 1986;6(5):753-791. https:///oi.org/10.1148/radiographics.6.5.3317550

3. Chevalier RL, Forbes MS, Thornhill BA. Formation of atubular glomeruli in the developing kidney following chronic urinary tract obstruction. Pediatr Nephrol 2011;26(9):1381-1385. https://doi org/10.1007/s00467-010-1748-y
4. Saphier CJ, Gaddipati S, Applewhite LE, Berkowitz RL. Prenatal diagnosis and management of abnormalities in the urological system. Clin Perinatol 2000;27(4):921- 945. https://doi.org/10.1016/ S0095-5108(05)70058-0

5. Mesrobian HO, Balcom AH, Durkee CT. Urologic problems of the neonate. Pediatr Clin North Am 2004;51(4):1051-1062. https://doi.org/10.1016/j.pcl.2004.03.016

6. Hassan JM, Pope JC, Brock JW, Adams MC. Vesicoureteral reflux in patients with posterior urethral 6. Hassan JM, Pope JC, Brock JW, Adams MC. Vesicoureteral reflux in patients with posterior
valves. J Urol 2003;170(4 Pt 2):1677-1680. https://doi.org/10.1097/01.ju.0000087491.16553.0d

7. Patti G, Naviglio S, Pennesi M, et al. Normal voiding does not exclude posterior urethral valves. Arch Dis Child 2013;98(8):634. https://doi.org/10.1136/archdischild-2013-304114

8. Farhat W, McLorie G, Capolicchio G, et al. Outcomes of primary valve ablation versus urinary tract diversion in patients with posterior urethral valves. Urology 2000;56(4):653-657. https://doi. org/10.1016/S0090-4295(00)00784-6

9. De Kort LMO, Uiterwaal CSPM, Beek EJA, et al. Reliability of voiding cystourethrography to detect urethral obstruction in boys. Urology 2004;63(5):967-972. https://doi.org/10.1016/j. urology.2003.11.047

10. De Jong TPVM, Radmayr C, Dik P, et al. Posterior urethral valves: Search for a diagnostic reference standard. Urology 2008;72(5):1022-1025. https://doi.org/10.1016/j.urology.2008.04.037

11. Rittenberg MH, Hulbert WC, Snyder HM, Duckett JW. Protective factors in posterior urethral valves. J Urol 1988;140(5):993-996. https://doi.org/10.1016/S0022-5347(17)41908-2

12. Aaronson IA. Posterior urethral valve: A review of 120 cases. S Afr Med J 1984;65(11):418-422. https:// . Aaronson IA. Posterior urethral valve: A review of 120 cases. S Afr Med J 1984;65(11):418-422
journals.co.za/content/m_samj/65/11/AJA20785135_10833 (accessed 25 February 2016).

13. Puri A, Grover VP, Agarwala S, Mitra DK, Bhatnagar V. Initial surgical treatment as a determinant of Puri A, Grover VP, Agarwala S, Mitra DK, Bhatnagar V. Initial surgical treatment as a determinant of
bladder dysfunction in posterior urethral valves. Pediatr Surg Int 2002;18(5-6):438-443. https://doi. bladder dysfunction in posterior
org/10.1007/s00383-002-0713-7

14. Strand WR. Initial management of complex pediatric disorders: Prunebelly syndrome, posterior urethral valves. Urol Clin N Am 2004;31(3):399-415. https://doi.org/10.1016/j.ucl.2004.04.010

15. Hubert KC, Palmer JS. Current diagnosis and management of fetal genitourinary abnormalities. Urol Clin N Am 2007;34(1):89-101. https://doi.org/10.1016\%2Fj.ucl.2006.10.002

16. Akdogen B, Dogan HS, Keskin S, Burgu B, Tekgul S. Significance of age-specific creatinine levels at presentation in posterior urethral valve patients. J Pediatr Urol 2006;2(5):446-452. https://doi, org/10.1016\%2Fj.jpurol.2005.10.007

17. Drozdz D, Drozdz M, Gretz N, Möhring K, Mehls O, Schärer K. Progression to end-stage renal disease in children with posterior urethral valves. Pediatr Nephrol 1998;12(8):630-636. https://doi. org/10.1007\%2Fs 004670050517

18. Ingraham SE, McHugh KM. Current perspectives on congenital obstructive nephropathy. Pediatr Nephrol 2011;26(9):1453-1461. https://doi.org/10.1007\%2Fs00467-011-1799-8
Nephraham SE, McHugh KM. Current perspectives on congenital obstructive

19. Narasimhan KL, Kaur B, Chowdhary SK, Bhalla AK. Does mode of treatment affect the outcome of neonatal posterior urethral valves? J Urol 2004;171(6 Pt 1):2423-2426. https://doi.org/10.1097\%2F01.

20. Godbole P, Wade A, Mushtaq I, Wilcox DT. Vesicostomy vs primary ablation for posterior urethral valves: Always a difference in outcome? J Pediatr Urol 2007;3(4):273-275. https://doi.org/10.1016\%2Fj. jpurol.2006.11.007

21. Glassberg KI. The valve bladder syndrome: 20 years later. J Urol 2001;166(4):1406-1414. https://doi.or $\mathrm{g} / 10.1016 \% 2 \mathrm{Fs} 0022-5347 \% 2805 \% 2965796-5$

22. Schwartz GJ, Furth SL. Glomerular filtration rate measurement and estimation in chronic kidney disease. Pediatr Nephrol 2007;22(11):1839-1848. https://doi.org/10.1007\%2Fs00467-006-0358-1

23. Hogg RJ, Furth S, Lemley KV, et al. National Kidney Foundation's Disease Outcomes Quality Initiative Clinical Practice Guidelines for Chronic Kidney Disease in Children and Adolescents: Evaluation, classification, and stratification. Pediatrics 2003:111(6 Pt 1):1416-1421. http://pediatrics. aappublications.org/content/111/6/1416.full.pdf (accessed 6 June 2008).

24. R Core Team. R: A language and environment for statistical computing. Vienna: R Foundation for Statistical Computing, 2017. https://www.R-project.org/ (accessed 11 July 2018).
St.

25. Stewart C. The magic of ultrasound. S Afr J Obstet Gynaecol 2011;17(3):54-55. http://www.sajog.org. . Stewart C. The magic of ultrasound. S Afr J Obstet Gynaecol 2011;17(3):54-55.
za/index.php/SAJOG/article/view/413/229 (accessed 13 September 2016).

26. Bajpai M, Dave S, Gupta DK. Factors affecting outcome in the management of posterior urethral valves. Pediatr Surg Int 2001;17(1):11-15. https://doi.org/10.1007\%2Fs003830000496

27. Chatterjee SK, Banerjee S, Basak D, et al. Posterior urethral valves: The scenario in a developing center. Pediatr Surg Int 2001;17(1):2- 7. https://doi.org/10.1007\%2Fs003830000495

28. Orumuah AJ, Oduagbon OE. Presentation, management, and outcome of posterior urethral valves in a Nigerian tertiary hospital. Afr J Paediatr Surg 2015;12(1):18-22. https://doi. org $/ 10.4103 \% 2 F 0189-6725.15093$

Accepted 21 February 2018. 